\title{
A Expansão da Mancha Urbana da Cidade de Guarapuava-PR, entre 1940 e 2016
}

\author{
The Urban Expansion of the city of Guarapuava-PR, during 1940 and 2016
}

La Expansión de la Mancha Urbana de la Ciudad de Guarapuava-PR, entre 1940 y 2016

\author{
Emerson de Souza Gomes ${ }^{1}$ \\ Leandro Redin Vestena ${ }^{2}$
}

\begin{abstract}
RESUMO: O presente trabalho teve por objetivo avaliar a expansão físico-territorial urbana de Guarapuava-PR, entre 1940 e 2016, por meio do mapeamento da ocupação urbana, utilizando-se de diversas fontes cartográficas e técnicas de geoprocessamento. A cidade de Guarapuava é de porte médio e localiza-se na região Centro-Sul do Estado do Paraná, região que apresenta baixa dinâmica econômica e os mais baixos IDH (Índices de Desenvolvimento Humano) do Estado do Paraná. Os dados utilizados para identificação da ocupação urbana em diferentes décadas foram cartas analógicas de loteamentos urbanos registrados, cartas topográficas, fotografias áreas e imagens de satélites. Os procedimentos metodológicos consistiram na integração e processamento dos diferentes dados cartográficos em um SIG (Sistema de Informação Geográfica). A expansão físico-territorial urbana de Guarapuava entre 1940 e 2016 deu-se em três fases distintas: até 1960, de 1960 a 1990, e após 1990. A primeira fase, até 1960 foi marcada por uma urbanização incipiente, com pequena taxa de expansão da área urbana; na fase de 1960 a 1990 por elevada taxa de urbanização na cidade, com significativa expansão das áreas urbanas; enquanto que a fase após 1990 é caracterizada pelo adensamento populacional.
\end{abstract}

PALAVRAS-CHAVE: Urbanização; Guarapuava; Expansão urbana.

ABSTRACT: This study aimed to evaluate the urban physical-territorial expansion in Guarapuava-PR during 1940 and 2016. It was based on mapping of urban occupation, using a variety of cartographic sources and GIS techniques. Guarapuava city is midsize and it is located in the south-central region of Paraná State, a region that has low economic dynamics and the worst HDI (Human Development Index) in Paraná State. Data used to identification of urban occupation in different decades was analogue letters of registered urban blends, topographic maps, aerial photography and satellite imagery. Methodological procedures consisted in integration and processing of different cartographic data in a GIS (Geographic Information System). The urban physical-territorial expansion of Guarapuava between 1940 and 2016 occurred in three distinct phases: until 1960, from 1960 to 1990 and after 1990. The first phase, until 1960, was marked by an incipient urbanization with small rate of expansion of the urban area; during 1960-1990 by the high rate of urbanization in the city with

\footnotetext{
${ }^{1}$ Universidade Estadual do Centro-Oeste. E-mail: souzagomesemerson@gmail.com. Endereço: Programa de Pós-Graduação em Geografia. Rua Camargo Varela de Sá, 03 - CEP 85040-080 - Guarapuava - Paraná - Brasil. 2 Universidade Estadual do Centro-Oeste. E-mail: Ivestena@unicentro.br. Endereço: Departamento de Geografia. Rua Camargo Varela de Sá, 03 - CEP 85040-080 - Guarapuava - Paraná - Brasil.
} 
significant expansion of urban areas, whereas the phase after 1990 is characterized by population increase.

KEYWORDS: Urbanization; Guarapuava; Urban expansion.

RESUMEN: Este estudio tuvo como objetivo evaluar la expansión física del área urbana de la localidad de Guarapuava-PR, entre 1940 y 2016, a través de la cartografía de la ocupación urbana, utilizando una variedad de fuentes cartográficas y técnicas de SIG. La ciudad de Guarapuava (de tamaño medio) está ubicada en la región centro-sur del estado de Paraná; esta región presenta una baja dinámica económica y el peor IDH (Índice de Desarrollo Humano) del Estado de Paraná. Los datos utilizados para la identificación de la ocupación urbana en diferentes décadas fueron cartas analógicas de loteos urbanos registrados, mapas topográficos, fotografías aéreas e imágenes satelitales. Los procedimientos metodológicos consistieron en la integración y elaboración de los diferentes datos cartográficos en un SIG (Sistema de Información Geográfica). La expansión física de la tierra urbana de Guarapuava entre 1940 y 2016 se produjo en tres fases distintas: hasta el año 1960, de 1960 a 1990 y después de 1990. La primera fase, hasta 1960, se caracterizó por una urbanización incipiente, con una pequeña tasa de expansión de la zona urbana, durante 1960-1990 por el alto índice de urbanización de la ciudad, con una importante expansión de las zonas urbanas, mientras que la fase a partir de 1990 es caracterizada por el incremento de la densidad de la población.

PALABRAS CLAVES: Urbanización; Guarapuava; Expansión urbana.

\section{INTRODUÇÃO}

No Brasil, a partir da década de 1960, o êxodo rural e a taxa de crescimento populacional elevada proporcionaram a concentração de um elevado número de habitantes nos núcleos urbanos. As cidades acabaram expandindo-se, na maioria das vezes, desordenadamente, sem um plano de ocupação dos espaços periféricos ao centro.

O processo de urbanização das cidades brasileiras, associado à ausência de planejamento, e a proliferação de ocupações irregulares ocasionaram uma série de problemas de ordem social e ambiental. São vários os problemas socioambientais que surgem pela forma como a urbanização ocorreu e ainda ocorre no Brasil (SPÓSITO et al., 2007).

Entre os vários problemas que podem ocorrer na cidade por conta da forma de uso e ocupação do seu espaço, destacam-se: a poluição atmosférica, sonora e dos recursos hídricos; a intensificação de processos erosivos; o aumento da frequência e amplitude dos alagamentos; e o aumento do número de desastres naturais. No caso brasileiro, a evolução da urbanização se deu de maneira intensa a partir da década de 1950, quando o índice de população urbana era de 36\%, chegando a 84\% em 2010 (IBGE, 2011), derivando de dois 
fatores principais: a concentração fundiária e a modernização do campo, os quais estimularam os fluxos migratórios para as cidades.

A cidade apresenta, em sua configuração territorial, uma ampla diferenciação de formas de uso, os espaços produtivos (industriais, comerciais e de serviços) e os residenciais; e uma diversidade de classes sociais. A materialização dessas formas no espaço urbano é diferenciada, na sua estrutura e qualidade de equipamentos coletivos e serviços disponibilizados à população (CORRÊA, 1995; SPÓSITO, 1988).

A desigualdade de infraestrutura urbana (presença ou ausência de vias de acesso, saneamento básico, energia elétrica etc.) e os aspectos físicos do terreno (áreas susceptíveis ou não a deslizamentos, inundações, alagamentos etc.) promovem uma valorização de algumas áreas em detrimentos de outras.

O crescimento horizontal da cidade ocorre convertendo as terras rurais em urbanas. De um modo geral, essa dinâmica é dirigida pelo parcelamento de chácaras e glebas rurais. Trata-se da lógica de transformação dos hectares rurais em metros quadrados urbanos. Esse aumento de superfície pode ocorrer também pela anexação de novos lotes, em sua maioria com edificações de um só andar, servindo como moradia e quase que exclusivamente para a população de baixa renda, pois a cidade passa a receber lavradores expropriados do campo, que chegam à busca de trabalho.

Outra forma de crescimento da cidade é por meio do processo de verticalização, que é vista como um marco revolucionário na paisagem urbana, capaz de produzir impactos significativos nas estruturas sociais e econômicas da cidade, pelas alterações provocadas no valor do uso do solo urbano (CORRÊA, 1995).

No município de Guarapuava, o processo de urbanização não foi diferente do contexto nacional, todavia deu-se tardiamente, mais especificadamente a partir da década de 1970. A intensidade da urbanização tornou as relações sociais e econômicas mais complexas em Guarapuava, proporcionando uma grande demanda por espaços de moradia, e ocasionou uma série de problemas socioambientais, como a poluição do solo e da água e a "marginalização de parte da população" (VESTENA; SCHMIDT, 2009, p. 69).

Os fatores econômicos e políticos foram os principais impulsionadores do desenvolvimento do município e do crescimento urbano em Guarapuava, uma vez que, desde sua formação, em 1819, até 1980, a população estava concentrada na área rural, cenário que foi drasticamente alterado a partir da década de 1970, pois a população urbana ultrapassa a rural.

Esta mudança esteve atrelada à inserção do Brasil na economia capitalista mundial; ao processo de modernização agrícola; e à integração de Guarapuava à economia nacional. 
Silva (1995) e Gomes (2012) discutem os processos desse momento histórico de transformações e a dinâmica das mudanças ocorridas no espaço urbano de Guarapuava de 1940 a 1990, bem como identificam a expansão da ocupação urbana ocorrida no período, levando-se em conta a implantação de loteamentos urbanos.

Contudo, a expansão urbana avaliada a partir dos loteamentos urbanos aprovados pela Prefeitura Municipal de Guarapuava (PMG) não identifica as ocupações urbanas efetivas, uma vez que muitas áreas não são oficialmente registradas na prefeitura, assim como áreas loteadas podem conter vazios urbanos, com o predomínio de atividades rurais. Neste sentido, existe uma lacuna de estudos sobre a expansão urbana de Guarapuava que identifique as áreas urbanas efetivamente ocupadas, principalmente após a década de 1960, período em que a urbanização se intensificou na cidade.

A expansão físico-territorial urbana é tida como o espaço efetivamente ocupado por edificações. A identificação das áreas efetivamente ocupadas com este tipo de uso subsidia estratégias de planejamento da cidade, no direcionamento de sua expansão, bem como na intensificação de áreas com baixa densidade populacional e dos vazios.

Guarapuava possui uma importante representatividade no contexto regional, sobretudo em relação aos aspectos econômicos e pela oferta de serviços. Se, a princípio sua influência esteve ligada à atividade primária, atualmente também está ligada ao setor terciário, pois atende às demandas de serviços dos municípios no seu entorno, principalmente de educação e saúde.

A presença diferenciada de um elevado contingente de pessoas ainda residindo no campo, na região Centro-Sul do Estado do Paraná, quando comparada às demais regiões, pode num futuro não muito distante potencializar um incremento significativo da população urbana, a partir do deslocamento para a cidade (centros urbanos) dessa população que ainda reside no campo. Daí a necessidade em planejar a ocupação urbana, a fim de direcioná-la para as áreas mais adequadas.

Neste contexto, ganham cada vez mais importância estudos que venham a contribuir na compreensão dos fenômenos ligados à ocupação e expansão dos espaços urbanos, sobretudo aqueles que oferecem subsídios para o planejamento do uso e da ocupação do solo na cidade. Os estudos sobre o espaço urbano têm sido realizados utilizando-se de diferentes instrumentos e metodologias; essas por sua vez, variam conforme o objetivo da análise. Dentre os instrumentos que se destacam para estudos voltados para o entendimento da expansão desse espaço, principalmente àqueles voltados para o planejamento físico-territorial da cidade, está o geoprocessamento. 
O geoprocessamento configura-se num conjunto de tecnologias de coleta e tratamento de dados espaciais e, como tal, torna-se uma importante ferramenta para vários estudos ambientais, dentre eles o estudo do espaço/ambiente urbano, sobretudo àqueles voltados ao planejamento físico-territorial da cidade, como mencionam Barros, Barros e Caviglione (2001) e Morato et al. (2011). Uma das vantagens da utilização do geoprocessamento para a análise da expansão é possibilitar a integração de informações de naturezas diversas como fotografias áreas, cartas topográficas e imagens de satélites, numa mesma base de dados espaciais.

O conhecimento da dinâmica têmpora-espacial da expansão físico-territorial urbana de Guarapuava vai contribuir com o entendimento das transformações no âmbito do espaço urbano, dos fatores responsáveis pela sua expansão em diferentes períodos e com sua tendência de expansão. A sociedade e os órgãos públicos cada vez mais carecem de conhecimento da direção ou direções de expansão da cidade e da natureza física das áreas possíveis de ocupação urbana para a tomada de decisão, no sentido de orientar essas direções de expansão urbana.

Dessa forma, o presente trabalho teve por objetivo avaliar a expansão físico-territorial urbana de Guarapuava entre 1940 e 2016, por meio do mapeamento da ocupação urbana, utilizando-se de técnicas de geoprocessamento.

\section{MATERIAIS E MÉTODOS}

\section{Área de Estudo}

Guarapuava situa-se na porção centro-sul do estado do Paraná (Figura 1). Sua área urbana está compreendida entre os paralelos $25^{\circ} 26^{\prime} 57^{\prime \prime}$ e $25^{\circ} 18^{\prime} 25^{\prime \prime}$ de latitude Sul e os meridianos $51^{\circ} 35^{\prime} 23^{\prime \prime}$ e $51^{\circ} 22^{\prime} 36$ " de longitude Oeste (Gw), com uma população estimada em 180.364 habitantes em 2017 (IBGE, 2018), dos quais cerca de 90\% está na cidade (162.000 habitantes). Sua economia tem como principal fonte de geração do PIB municipal, de $R \$ 3.582 .847,13$, o setor de serviços (68\%), seguido da indústria (25\%) e da agropecuária (8\%), segundo dados referentes a 2015 (IBGE, 2018).

Embora ainda esteja em processo de ampliação e qualificação das atividades terciárias, a cidade de Guarapuava possui o papel de polo regional na região Centro-Sul do Estado do Paraná, já que os demais municípios de seu entorno são carentes em serviços de educação, saúde e comércio, principalmente. Os municípios polarizados por Guarapuava na microrregião são formados por características bem particulares, como os mais baixos 
Índices de Desenvolvimento Humano; as maiores concentrações de terra; com a maior proporção de beneficiários do Bolsa Família; tem a pior relação entre o número de carteiras assinadas e a população total, sendo ainda, em seu conjunto pouco expressivos, sobretudo, pela sua baixa dinâmica econômica.

Figura 1 - Localização da área urbana de Guarapuava

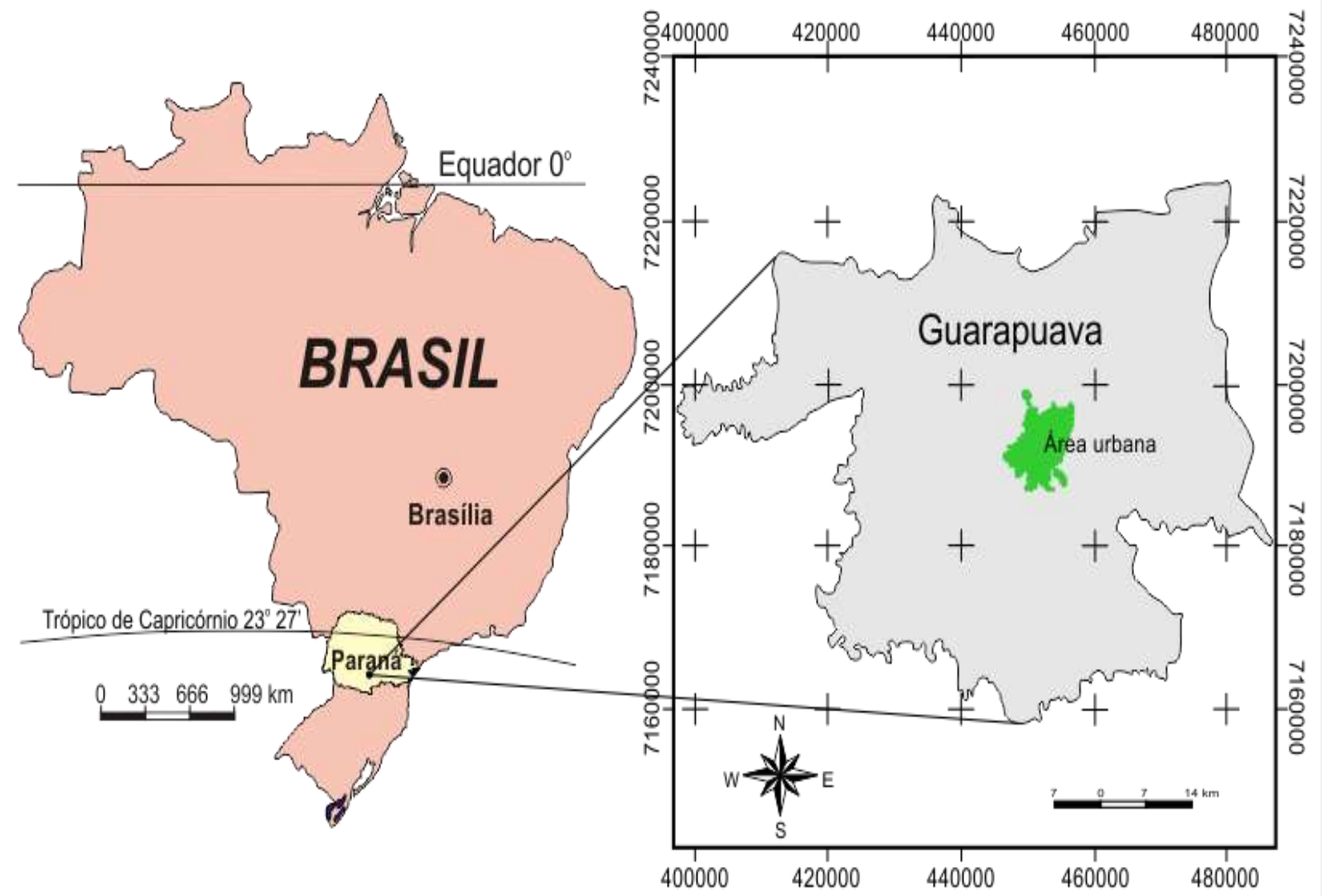

Fonte: organizada pelos autores a partir de: IBGE, 2013.

\section{Procedimentos Metodológicos}

Para a realização deste trabalho foram adotados os seguintes procedimentos metodológicos, divididos em três etapas, sendo respectivamente: a) revisão bibliográfica e levantamento de dados cartográficos; b) inserção dos dados cartográficos em um banco de dados, com o processamento de um Sistema de Informação Geográfica - SIG; e c) execução de alguns trabalhos de campo para verificação e validação dos dados.

Os materiais cartográficos e imagéticos utilizados foram: a) cartas topográficas da Diretoria de Serviço Geográfico do Exército Brasileiro, articulações MI-2837/4 e MI-2838/3 da folha SG.22-V-D-III-3, na escala 1:50.000, cedidas pelo Departamento de Geografia - 
Degeo da Unicentro, em meio analógico; base cartográfica em meio digital contendo a malha urbana, o perímetro urbano oficial, os rios principais e a divisão de bairros, na escala de 1:12.500, cedida pelo Centro de Estudos e Planejamento Urbano de Guarapuava Ceplug (GUARAPUAVA, 1996); fotografias aéreas do ano de 1995 na escala de 1:8000, cedidas pelo Ceplug em meio digital (GUARAPUAVA, 1996); Imagem orbital do satélite LANDSAT 7 ETM+, órbita 222, no ponto 78 de 28/06/2002, nas bandas 3 (vermelho), 4 (infravermelho próximo) e 5 (infravermelho médio), com resolução espacial de 30×30m, disponibilizadas gratuitamente, pelo Instituto Nacional de Pesquisas Espaciais - INPE, em meio digital; imagem orbital do satélite CBERS 2 (Satélites Sino-Brasileiros de Recursos Terrestres), sensor CCD (Couple Charged Device), órbita 159, ponto 128, de 11/07/2005, nas bandas espectrais verde, vermelho, infravermelho próximo, com resolução espacial de $20 \times 20 m$, disponibilizadas gratuitamente, pelo Instituto Nacional de Pesquisas Espaciais INPE, em meio digital; imagem orbital do sistema RapidEye, captada no dia 27/09/2011, abrangendo a área urbana de Guarapuava e seu entorno, nas bandas espectrais azul, verde e vermelho, com resolução espacial de $5 \times 5 \mathrm{~m}$, cedida pelo Laboratório de Estudos do Ambiente, Cultura e Desenvolvimento Local - Lecad da Unicentro, em meio digital; imagem orbital do sistema Sentinel-2, obtida em 18/11/2016, nas bandas espectrais B02 (Azul), B03 (Verde) e B04 (Vermelho), com resolução espacial de 10x10m, disponibilizadas gratuitamente pela Agência Espacial Europeia - ESA (ESA, 2017).

Utilizando-se do software SPRING - INPE@ Versão 5.2.1 - Sistema de Processamento de Informações Georreferenciadas (Copyright), desenvolvido pela Divisão de Processamento de Imagens - DPI do INPE, os dados cartográficos e as imagens de satélites foram integrados num SIG. O uso do SIG permitiu a integração das diferentes fontes de dados espaciais, a partir da entrada, do armazenamento, do tratamento, do processamento digital das imagens dos sensores orbitais, e da exibição de informações geográficas, topologicamente estruturadas, associadas a um banco de dados alfanumérico (CÂMARA et. al., 1996).

As imagens dos sensores orbitais foram avaliadas utilizando-se da associação de suas bandas espectrais em uma composição nos canais de cores Red $(\mathrm{R})$ (vermelho), Green $(\mathrm{G})$ (verde) e Blue (B) (azul), gerando-se imagens sintéticas, após uso de técnicas de contraste.

Para a imagem do sensor LANDSAT TMT, utilizou-se a composição banda 3 canal vermelho, banda 4 verde e banda 5 azul. Em relação à imagem do satélite CBERS 2, a composição empregada foi banda 3 vermelho, banda 4 verde e banda 2 azul. Essas associações possibilitaram a diferenciação da área urbana. 
A imagem do RapidEye em formato TIFF - Tagged Image File Format foi tratada utilizando-se da associação dos canais RGB às bandas espectrais vermelho, verde e azul, respectivamente. Para o trabalho com as Bandas 02, 03 e 04 do sistema Sentinel 2 optou-se pela combinação de bandas cor verdadeira RGB 04/03/02.

Os polígonos de expansão urbana dos anos de 1940, 1950, 1960 e 1970 tiveram por base cartas analógicas da área urbana publicados por Silva (1995) em seu trabalho de mestrado, as quais correspondem às áreas de loteamentos regulamentados junto à Prefeitura Municipal de Guarapuava e registradas em cartórios. Foram digitalizadas em ambiente SIG, para definição de suas áreas e perímetros.

As cartas topográficas da DSG de 1980 e 1990 (BRASIL, 1980a, 1980b, 1990a, 1990b), foram digitalizadas e inseridas no banco de dados em ambiente SIG. A partir destas, executou-se a edição vetorial para se estabelecer os perímetros e a áreas urbanas dos respectivos anos.

A partir da interpretação visual das imagens, foi realizada a identificação e a delimitação do perímetro da área urbana para os períodos de 1995, 2002, 2005, 2011 e 2016. Utilizou-se como critério a identificação de áreas, conforme os elementos de interpretação - tonalidade/cor, textura, tamanho, forma, sombra, altura e profundidade, volume, declividade, sítio, associação, padrão e localização (FLORENZANO, 2002; JENSEN, 2009), o que permitiu a identificação de regiões da cidade onde se estabeleceram novos loteamentos e novas edificações, nas áreas do limite perimetral, nos intervalos de tempo de acordo com os dados dos sensores remotos supracitados.

O mapeamento da área urbana de Guarapuava foi validado a partir de dados de campo do Sistema de Posicionamento Global, obtidos com o auxílio de um GPS (Global Positioning System), marca Garmin, modelo Map 76CSX.

A partir do módulo SCARTA do SPRING foram editadas as cartas para cada período, entre 1940 e 2016, com vistas à produção da carta de expansão urbana. Para a comunicação cartográfica, utilizou-se da variável cor e representação ordenada (MARTINELLI, 1998).

\section{RESULTADOS E DISCUSSÕES}

A expansão física territorial da cidade de Guarapuava entre 1940 e 2016 apresentou três fases distintas de evolução: uma até a década de 1960, de 1970 a 1990 e após 1990. 


\section{Até 1960: uma urbanização incipiente}

O município de Guarapuava em 1960 contava com uma população de 96.947 habitantes, sendo que 80.585 (83,12\%) residiam no campo, enquanto que, na cidade, 16.362, 16,88\% (IBGE, 2013). Pode-se afirmar que a cidade de Guarapuava, até os meados do século $X X$, foi, de certa maneira, uma extensão do campo.

A dinâmica urbana até a década de 1960 era restrita à vida social, política, cultural e comercial da elite, composta pelos fazendeiros que passaram a usufruir de capital acumulado com o tropeirismo e da renda que obtinham da erva-mate. Isso fez com que, apesar de certo incremento nas atividades urbanas, o crescimento físico-territorial urbano não fosse significativo (Figura 2). Houve concentração de equipamentos e serviços coletivos urbanos na porção central, e a formação de uma periferia pobre, carente em termos de infraestrutura.

Figura 2 - Área urbana de Guarapuava-PR, em 1940, 1950 e 1960.

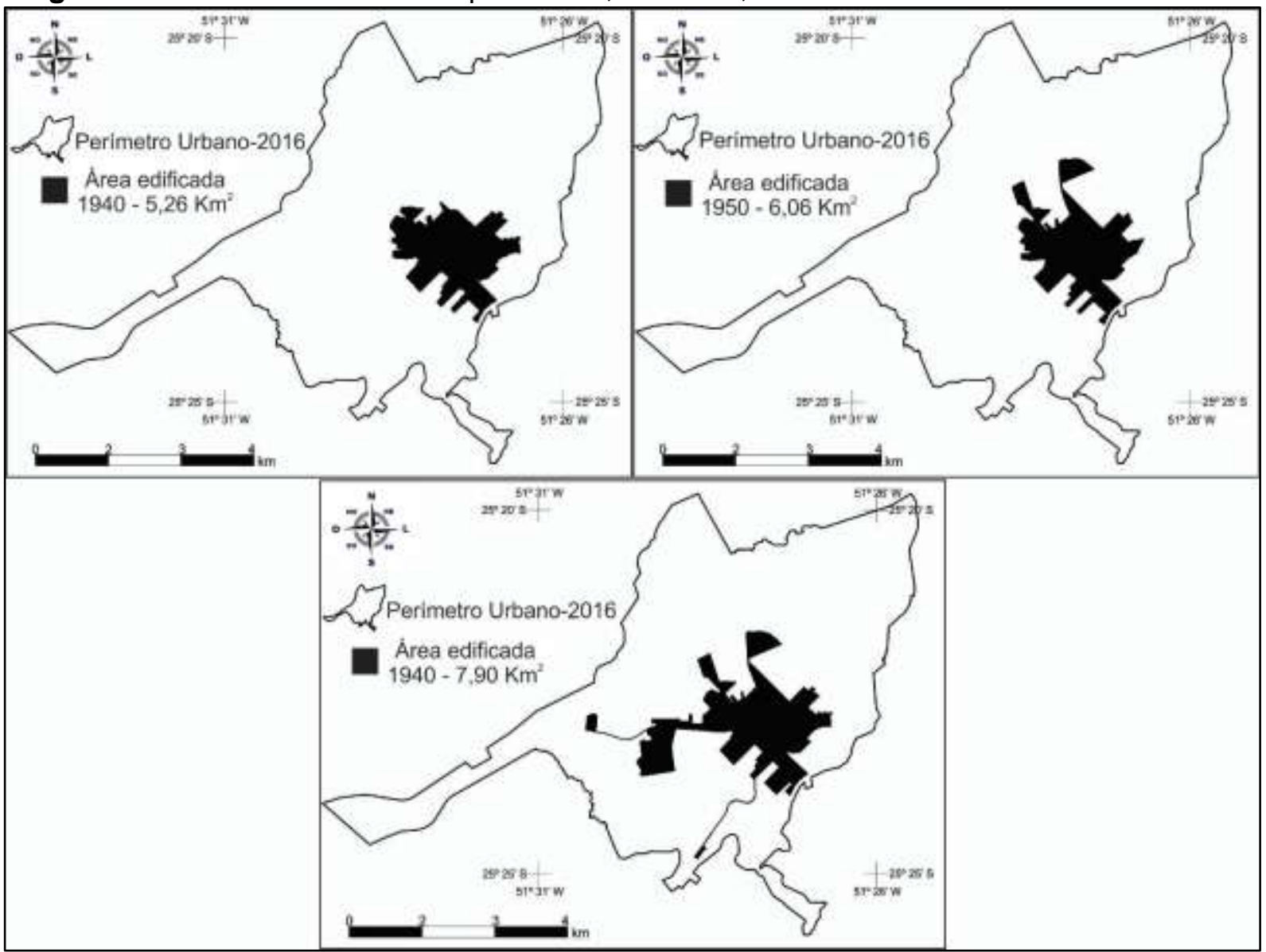

Fonte: organizado pelos autores a partir de: Guarapuava, 2016; Silva, 1995. 


\section{De 1960 a 1990: expansão horizontal e urbanização}

Nesta fase, a população urbana residindo no munícipio ultrapassa a rural. Tal mudança deve-se basicamente ao êxodo rural. Em Guarapuava, esta mudança seguiu o mesmo padrão da maioria dos municípios brasileiros, porém anos mais tarde. Na figura 3 tem-se a evolução da população urbana e rural em Guarapuava e no Brasil. Tal fato (o êxodo rural) ocasionou um incremento de população que passou a residir na cidade, o que levou, nesta fase, a um aumento significativo da área urbana.

Figura 3 - Evolução da população urbana e rural no Brasil (a) e em Guarapuava-PR (b)

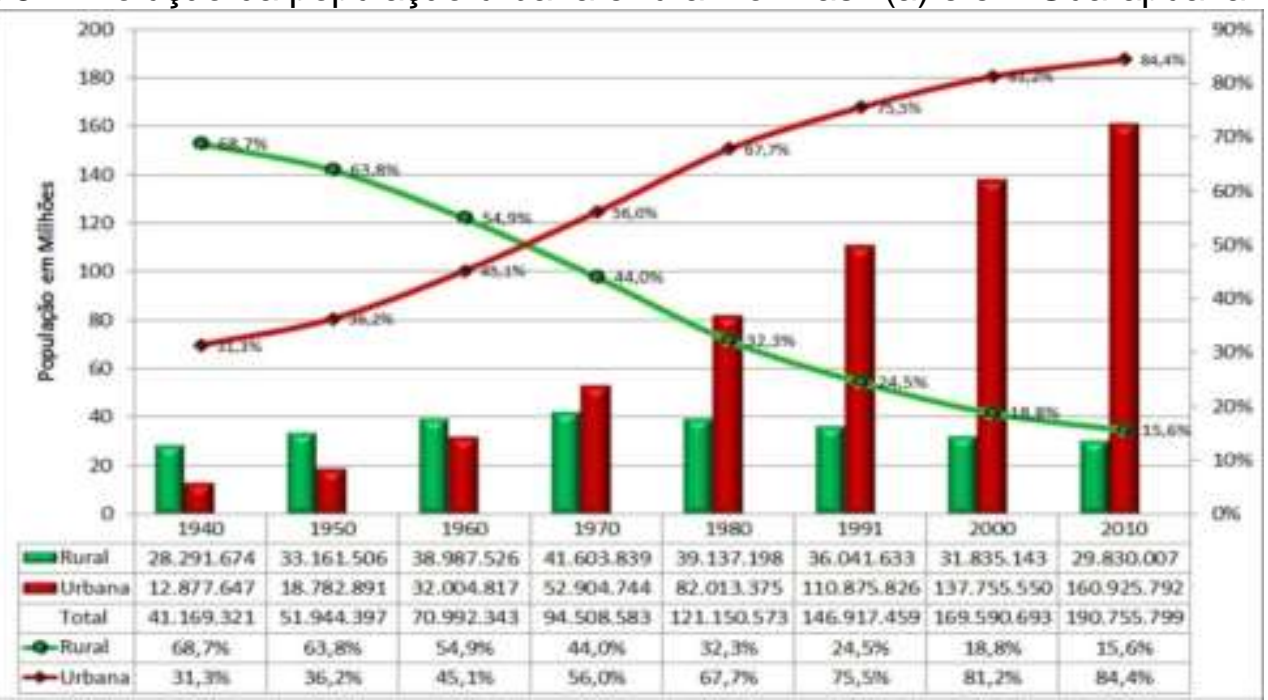

(a)

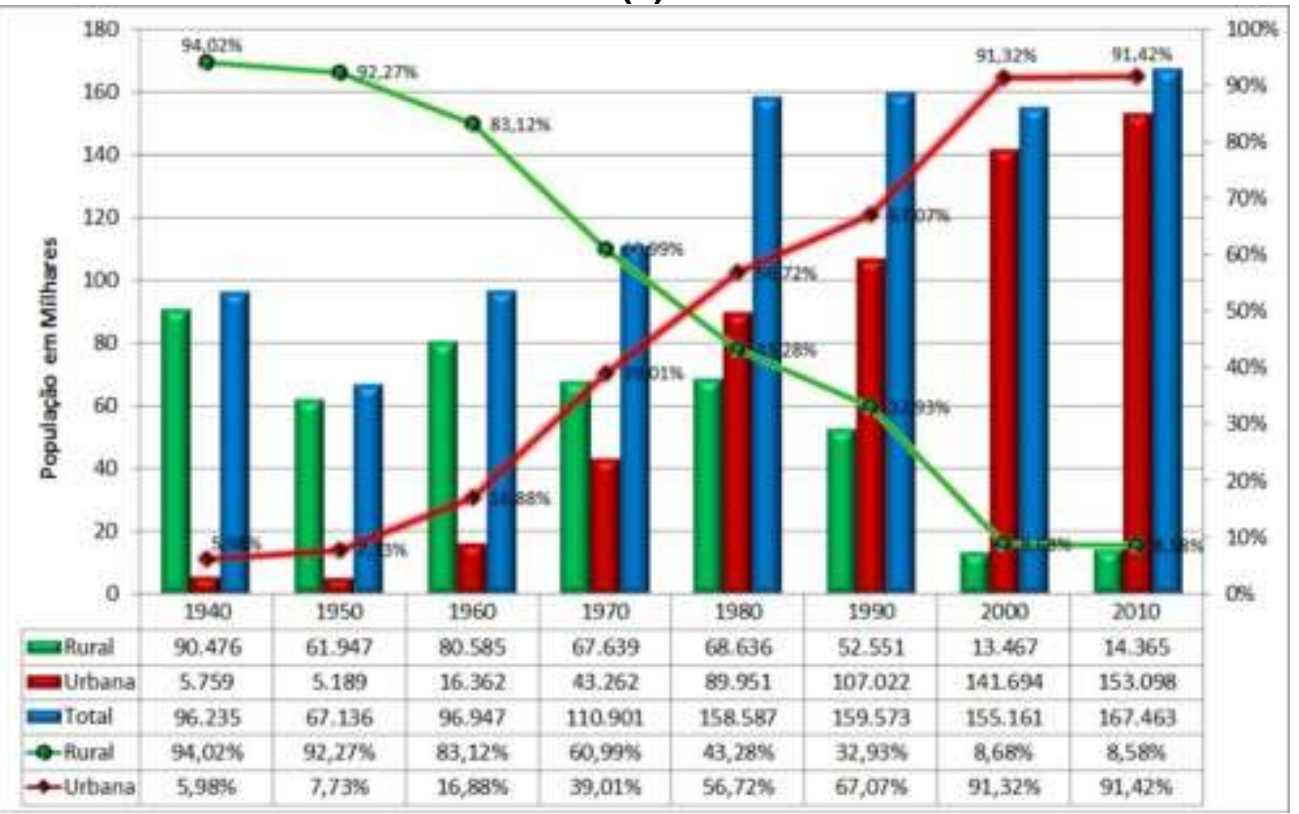

(b)

Fonte: organizado pelos autores a partir de: IBGE, 2013. 
O período entre meados da década de 1980 e o final do século XX foi marcado por novas formas de articulação da economia brasileira ao capitalismo internacional, estabelecendo a caracterização das cidades médias brasileiras (SPÓSITO, 2001). Guarapuava, na atualidade, pelo aspecto funcional, enquadra-se neste contexto, ou seja, continuamente encontra-se agregada ao significado de seus papéis regionais e ao potencial de comunicação e articulação, proporcionado por sua situação geográfica, tendo o consumo uma função mais importante que a produção na estruturação dos fluxos que definem o seu papel intermediário.

A reorganização da economia regional em virtude da modernização agrícola esteve atrelada à especialização do setor terciário e concentração de serviços urbanos. A modernização da agricultura tornou os tradicionais esquemas de comercialização inviáveis, acarretando em uma desestruturação do setor comercial dos municípios vizinhos, assim Guarapuava surge no papel de polo (SILVA, 1995).

Dentro de um sistema de desenvolvimento de uma agricultura comercial voltado para os mercados nacional e internacional, a cidade passa a exercer um poder de comando das relações econômicas, que acarretaram no processo de urbanização da região (SILVA, 1995).

De 1970 a 1990, registrou-se crescimento em quase $100 \%$ na população urbana, índice provocado por um intenso fluxo migratório para o município de Guarapuava, pois a região ainda era uma fronteira agrícola dentro do Estado do Paraná; porém, entre os anos de 1980 a 1990, os fluxos do êxodo rural continuam proporcionando aumento da população urbana, apesar de neste período a população no município não apresentar crescimento significativo, mais especificamente, aumentou 986 habitantes, enquanto a população urbana 17.071 habitantes (Figura 4).

A população, expropriada do campo pela modernização da agropecuária, ao se dirigir à cidade, não encontrou infraestrutura e habitações suficientes, não sendo rara a apropriação de terras em áreas sem acesso a serviços básicos, como água, energia elétrica, pavimentação etc. Essa mesma população enfrentou a falta de emprego e, consequentemente, a exclusão social por não apresentar qualificação técnica para os trabalhos urbanos. A combinação destes fatores revela-se na paisagem, pela ocupação de fundos de vale e/ou de habitações precárias nas periferias.

Esse aumento populacional promoveu uma expansão significativa da área urbana de Guarapuava, passando de 16,54 quilômetros quadrados, em 1970, à 34,85 quilômetros quadrados em 1990. 
Figura 4 - Área urbana de Guarapuava-PR, em 1970, 1980, e 1990

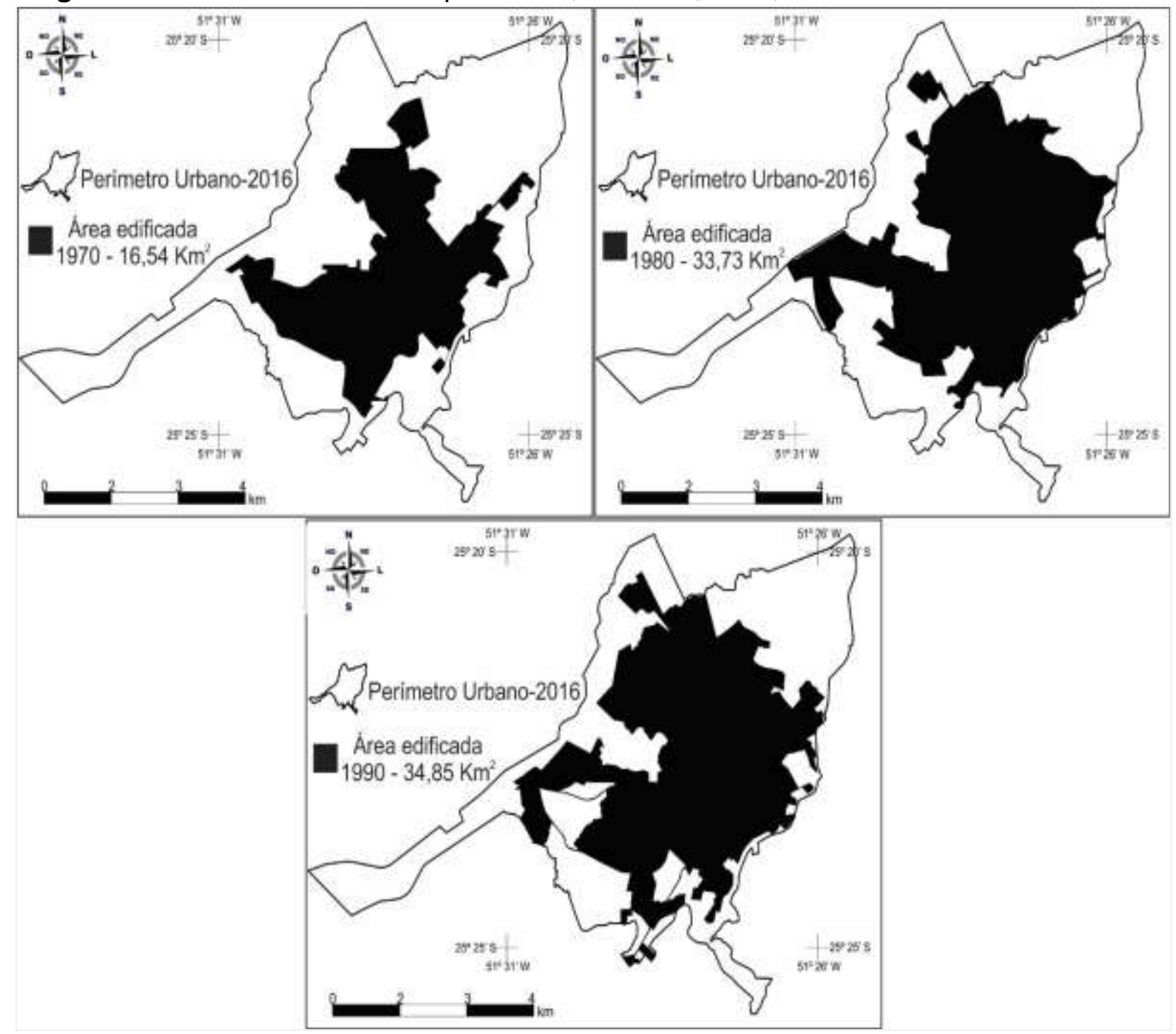

Fonte: organizado pelos autores a partir de: Brasil, 1980a; 1980b; 1990a, 1990b; Silva, 1995.

Nas décadas seguintes, após 1990, a tendência de expansão da área urbana de Guarapuava não se reduziu e, embora o poder público tenha buscado suprir estas demandas, a falta de planejamento inicial contribuiu para a não superaração de problemas estruturais decorrentes da ocupação desordenada de áreas periféricas à malha urbana.

\section{Após 1990: adensamento de ocupações (densificação)}

$\mathrm{Na}$ fase após 1990, verificou-se um adensamento na área urbana por meio da ocupação de áreas que contavam com estruturação, principalmente por meio de loteamentos em áreas vazias no centro da cidade e proximidades. Essa característica fez 
com que a expansão físico-territorial da área urbana tivesse seu ritmo desacelerado, quando comparado com a fase anterior.

Os poucos investimentos públicos no setor de habitação, em loteamentos na periferia, resultaram em aumento significativo das ocupações irregulares (em áreas não aptas a ocupação, como os fundos de vale e em Áreas de Preservação Permanente - APPs).

Outro fator que contribuiu para a ocupação de áreas já dotadas de infraestrutura foi a Lei Municipal n. 45/1987, de 24 de dezembro de 1987, passando a exigir a implementação de infraestrutura nos loteamentos e reserva de $35 \%$ da área para projetos de equipamentos coletivos (escola, creche, posto de saúde e outros), o que reduziu demasiadamente os investimentos em novas áreas a serem loteadas (GUARAPUAVA, 1987).

Guarapuava, nesta fase, se consolida com um polo regional, em razão de ter-se configurado na cidade um centro universitário (UNICENTRO e demais faculdades), uma referência para compras e pelo atendimento de serviços, principalmente de educação (colégios particulares e escolas técnicas), saúde ( $5^{\text {a }}$ Regional de Saúde, hospitais, clínicas médicas de especialidades e de diagnósticos) e ainda por ter sedes de importantes secretarias estaduais, como de habitação, saúde, educação e abastecimento, dentre outras.

Portanto, a ratificação deste papel de Guarapuava no contexto regional promoveu um salto na urbanização, no qual em 1990 se registrou 67,07\% de moradores na cidade para 2000, no qual o índice era de $91,32 \%$, mesmo com a diminuição da população total do município de 159.573 para 155.161 habitantes (fato que teve a influência do desmembramento do município de Campina do Simão, com cerca de 4.000 habitantes).

Percebe-se a necessidade do aumento de habitações na cidade de Guarapuava; no entanto, constata-se que os investimentos foram aquém da necessidade, o que proporcionou a configuração de um quadro urbano, cujo território se dissipou por meio de ocupações irregulares nas suas porções periféricas, caracterizada por moradias com padrão inferior se comparadas com as localizadas próximas ao centro da cidade (Figura 5).

Em 1990, a população urbana em Guarapuava passa a ter mais de 100 mil habitantes, limiar apontado por Santos (1993). Para caracterização de cidade média, Coredi e Ferreira (2013, p. 120) destacam que "[...] a expansão e a diversificação do consumo, a elevação dos níveis de renda, a difusão dos meios de transporte e a divisão do trabalho mais acentuada" passam também a caracterizar as cidades médias. Todavia, de acordo com os autores, em nível intraurbano, Guarapuava apresenta problemas socioambientais e grande desigualdade na distribuição de renda e de acesso à terra urbana, que se tornam obstáculos à sua qualificação como cidade de porte médio. 
Figura 5 - Área urbana de Guarapuava-PR, em 1995, 2002, 2005, 2011 e 2016

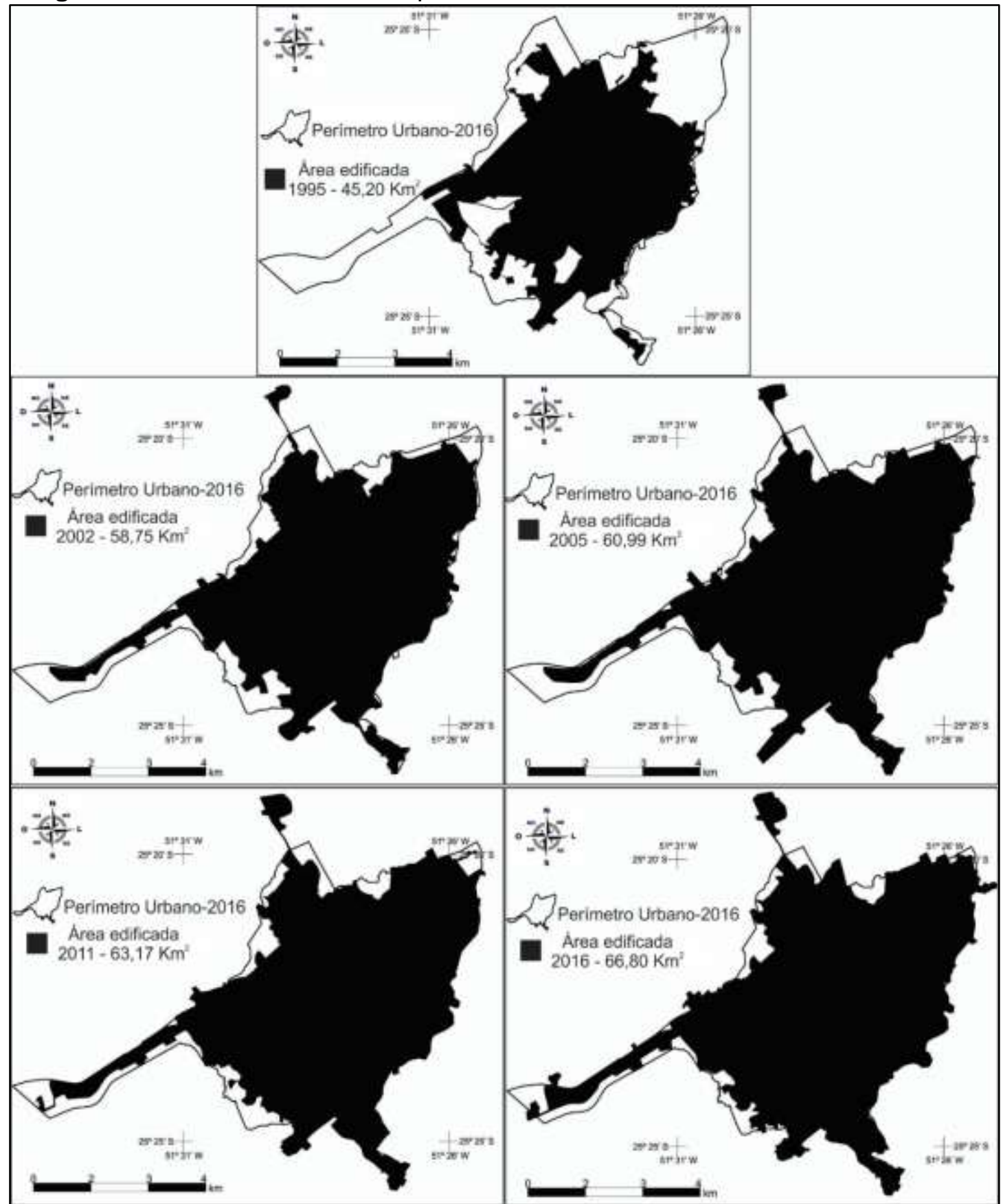

Fonte: Organizado pelos autores a partir de: CBERS..., 2005; ESA, 2017; Guarapuava, 1996; Landsat..., 2002; Rapideye, 2011.

\section{A expansão urbana de Guarapuava}

Na Figura 6 e no Quadro 1 têm-se os dados obtidos do mapeamento da área urbana de Guarapuava nos anos de 1940, 1950, 1960, 1970, 1980, 1990, 1995, 2002, 2005, 2011 e 2016. 
Figura 6 - Expansão da área urbana de Guarapuava-PR entre 1940 e 2016

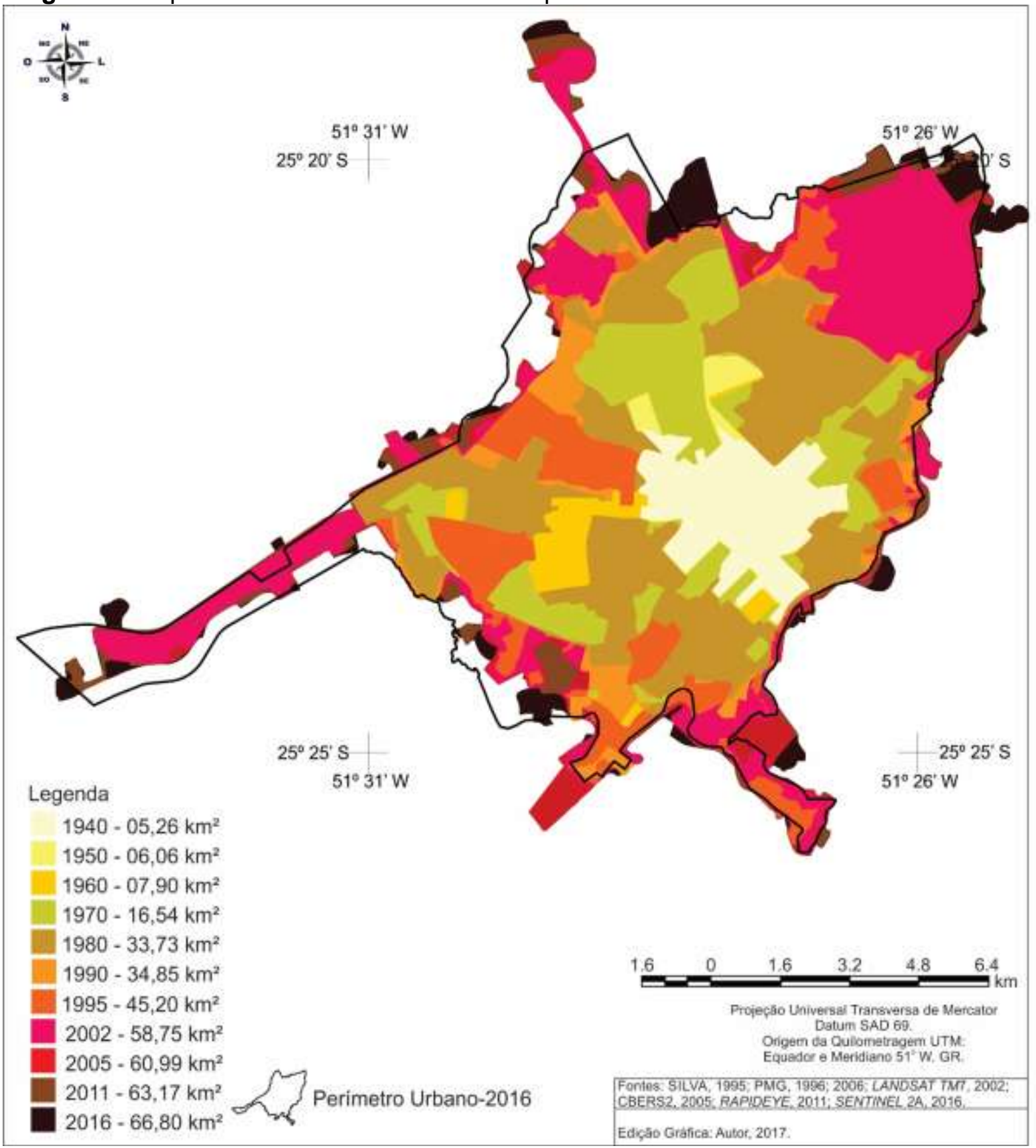

Fonte: Organizado pelos autores (2017).

A área urbana de Guarapuava de 1940 a 1960 apresentou crescimento, contudo um crescimento relativamente pequeno se comparado com os das décadas posteriores. $\mathrm{Na}$ década de 1950, o crescimento deu-se na direção Norte e na de 1960 na direção Oeste. Na década de 1950, o número de habitantes na cidade de Guarapuava apresentou um pequeno decréscimo; porém, na década seguinte, a população urbana triplicou de tamanho, com 
aumento significativo na densidade demográfica urbana, que era de aproximadamente 850 em 1950 e passa a 2.100 hab./km², em 1960.

O decréscimo na população urbana na década de 1940 deu-se associado à estagnação econômica de Guarapuava frente à outras regiões paranaenses (Londrina, Maringá e Cascavel), que passaram a atrair população, e aos diversos desmembramentos ocorridos do município de Guarapuava (Pitanga em 1943 e Laranjeiras do Sul em 1946). Nesse período, a economia de Guarapuava era baseada essencialmente no extrativismo, principalmente da erva-mate.

A década de 1970 foi o período em que ocorreu o maior aumento da mancha urbana de Guarapuava, com crescimento de $109,63 \%$ em relação à década de 1960. Nessa década, a área urbana se expandiu em todas as direções, com maior predomínio nas direções Norte, Noroeste e Sudoeste, período em que a população urbana ultrapassou a rural no município. Na década de 1980, a expansão se deu em todas as direções, período em que também se teve considerável expansão da área urbana, juntamente com a década de 1970 (Quadro 1).

Quadro 1 - Síntese da evolução da expansão da cidade de Guarapuava-PR

\begin{tabular}{|c|c|c|c|c|c|c|c|c|c|}
\hline \multirow{2}{*}{$\begin{array}{l}\text { Data } \\
\text { (ano) }\end{array}$} & \multirow{2}{*}{$\begin{array}{c}\text { Área } \\
\text { Urbana } \\
\left(\mathbf{k m}^{2}\right)\end{array}$} & \multirow{2}{*}{$\begin{array}{l}\text { Pop. } \\
\text { Urbana } \\
\text { (hab.) }\end{array}$} & \multicolumn{2}{|c|}{$\begin{array}{l}\text { Expansão } \\
\text { Urbana }\end{array}$} & \multirow{2}{*}{$\begin{array}{l}\text { Direção (ões) } \\
\text { predominantes } \\
\text { da Expansão }\end{array}$} & \multicolumn{2}{|c|}{$\begin{array}{l}\text { Crescimento da } \\
\text { Pop. Urbana }\end{array}$} & \multirow{2}{*}{$\begin{array}{c}\text { Densidade } \\
\text { da Pop. } \\
\text { Urbana } \\
\left(\mathbf{h a b} . / \mathbf{k m}^{2}\right) \\
\end{array}$} & \multirow{2}{*}{$\begin{array}{c}\text { Fase de } \\
\text { expansão } \\
\text { urbana }\end{array}$} \\
\hline & & & $\left(\mathrm{km}^{2}\right)$ & (\%) & & (hab.) & (\%) & & \\
\hline 1940 & $5,26^{1}$ & 5.759 & $* *$ & $\star \star$ & ** & $* *$ & $\star \star *$ & $1.096,77$ & \multirow{3}{*}{ Até 1960} \\
\hline 1950 & $6,06^{1}$ & 5.189 & 0,80 & 15,21 & Norte & -570 & $-9,90$ & 856,27 & \\
\hline 1960 & $7,89^{1}$ & 16.362 & 1,83 & 30,20 & Oeste & 11.173 & 215,32 & $2.107,88$ & \\
\hline 1970 & $16,54^{1}$ & 43.264 & 8,65 & 109,63 & $\begin{array}{l}\text { Norte, Noroeste } \\
\text { e Sudoeste }\end{array}$ & 26.092 & 164,43 & $2.637,48$ & \multirow{3}{*}{$\begin{array}{c}1960 \mathrm{a} \\
1990\end{array}$} \\
\hline 1980 & 33,73 & 89.951 & 17,19 & 104,00 & $\begin{array}{l}\text { Todas as } \\
\text { direções }\end{array}$ & 76.687 & 578,16 & $2.653,42$ & \\
\hline 1990 & $34,85^{1}$ & 107.022 & 1,12 & 3,32 & Sul & 17.071 & 18,98 & $3.070,93$ & \\
\hline 1995 & 45,20 & * & 10,38 & 29,78 & $\begin{array}{l}\text { Noroeste e } \\
\text { Oeste }\end{array}$ & * & * & * & \multirow{5}{*}{ Após 1990} \\
\hline 2002 & 58,75 & 141.694 & 13,55 & 29,98 & $\begin{array}{l}\text { Norte e } \\
\text { Nordeste }\end{array}$ & 34.672 & 32,40 & $2.430,01$ & \\
\hline 2005 & 60,99 & * & 2,24 & 3,81 & $\star * * *$ & * & * & * & \\
\hline 2011 & 63,17 & 153.098 & 2,18 & 3.57 & $* * *$ & 11.404 & 8,05 & $2.364,81$ & \\
\hline 2016 & 66,80 & * & 3,63 & 5,75 & $\begin{array}{l}\text { Norte e } \\
\text { Nordeste }\end{array}$ & * & * & * & \\
\hline
\end{tabular}


Após a década de 1990, a expansão urbana passa a apresentar um ritmo menos intenso do que nas décadas de 1970 e 1980, com expansão por década inferior a 30\% em 1995 e 2002, e não superior a 7\% em 2005 e 2011.

A partir da década de 1960, a densidade populacional urbana na cidade de Guarapuava passou a ser superior a $2.000 \mathrm{hab} . / \mathrm{km}^{2}$, com maior adensamento na década de 1990 , onde se teve mais de $3.000 \mathrm{hab} . / \mathrm{km}^{2}$.

Na década de 1990, a direção da expansão urbana predominante foi a Sul. Já no ano de 1995 verificou-se uma expansão para a direção Oeste e Noroeste e, em 2002 para Norte e Nordeste (implantação do Conjunto Habitacional 2000). Um dos fatores da mudança no sentido do crescimento de Sul para Noroeste, Oeste, Norte e Nordeste deve-se à área de manancial da cidade estar localizada ao Sul e estar limitada a porções com declividades acentuadas.

Além da expansão e do adensamento, percebeu-se também novas ocupações urbanas em praticamente todas as direções, ou seja, houve a extrapolação do limite do perímetro urbano de 1995 quando comparado com o de 2002.

Em 2002, a área havia se expandido para 58,75 quilômetros quadrados, o que representou aumento de 13,55 quilômetros quadrados, ou seja, quase $30 \%$ no período de sete anos (1995 a 2002). O crescimento da área urbana deu-se principalmente nas direções Norte e Nordeste, com adensamento interno na porção Oeste. A área urbana da cidade de Guarapuava em 2011 era de 64,76 quilômetros quadrados, onde residem 153.098 habitantes, apresentando uma densidade demográfica de $2.364,81$ hab./km².

Entre 2011 (27/09/2011) e 2016 (18/11/2016) observou-se um aumento de cerca de $6 \%$ na área urbana construída, o que significou uma amplificação dobrada em relação aos períodos anteriormente examinados (2002-2005; 2005-2011). Isso se deve em parte pela ocupação de duas áreas rurais periféricas: uma na região nordeste, e outra, na porção norte. Na porção norte, em função principalmente de obras de iniciativa estatais como a sede da Universidade Tecnológica Federal do Paraná - UTFPR e o Hospital Regional (este ainda em fase de construção). E na nordeste, de empreendimentos privados, como a construção de um Shopping Center, um hipermercado, e um loteamento.

A densidade populacional na cidade de Guarapuava esteve diretamente ligada à expansão urbana nas décadas em que a expansão urbana foi pequena comparada ao crescimento da população urbana que teve aumento na densidade populacional. Na década de 1950 , este índice era de 856,27 hab. $/ \mathrm{km}^{2}$ e passou a $2.107,88 \mathrm{hab} . / \mathrm{km}^{2}$ na década de 1960, aumentando para a casa dos 2.600 hab. $/ \mathrm{km}^{2}$ nas duas décadas seguintes (1970 e 1980). No entanto, é em 1990 que essa taxa foi maior, 3.070,93 hab./km², uma vez que a 
população urbana era em torno de $19 \%$ maior que no período anterior e a área de expansão da cidade cresceu apenas $2,80 \%$. Com uma taxa de urbanização próxima de $91 \%$, Guarapuava apresenta redução de sua taxa de densidade demográfica urbana, uma vez que houve aumento proporcional maior da área urbana em relação aos habitantes da cidade. Enquanto que, entre 1990 a 2011, a área urbana cresceu aproximadamente $70 \%$ e a população urbana $59 \%$.

\section{CONCLUSÕES E CONSIDERAÇÕES FINAIS}

As análises multitemporais, a partir de diferentes fontes de dados de sensoriamento remoto (imagens orbitais e fotografias aéreas), integradas em um banco de dados em ambiente SIG, permitiram avaliar as áreas de expansão urbana de Guarapuava. A vantagem da geotecnologia está em oferecer um conjunto de ferramentas, especialmente o SIG, que possibilita a integração de dados de naturezas e escalas diferenciadas, além de oferecer, dentre a sua gama de potencialidades, ferramentas para a geração de cartas temáticas, o tratamento e a quantificação de dados.

A expansão físico-territorial da cidade se deu em três fases: até 1960; 1970 a 1990 e após 1990, associadas principalmente aos aspectos econômicos. Até 1960, a cidade possuía um papel pouco representativo regionalmente, uma vez que sua dinâmica até a década era restrita à vida social, política, cultural e comercial da elite local, fazendeiros da sociedade campeira tradicional.

De 1960 a 1990, Guarapuava se caracterizou pela formação de um polo regional, pois sua posição geográfica e vias de acesso, como a BR 277 , que faz a ligação Leste-Oeste do estado com a capital e a estrada de ferro, foram fatores preponderantes para a mudança da economia regional atrelada à modernização das atividades agropecuárias. Modernização essa que, por sua vez, acarretou uma mudança no papel da cidade, que passou a concentrar atividades terciárias. Nesta fase, a área urbana teve considerável expansão físico-territorial, e a população urbana ultrapassou a rural.

Após 1990, a cidade de Guarapuava ratifica seu papel de polo regional, por meio de atendimento de serviços ligados, principalmente, à educação e à saúde, e por se tornar uma referência para compras. É nesta fase que a urbanização se consolida em Guarapuava. $O$ ritmo do crescimento horizontal da área urbana de Guarapuava foi menor que na fase anterior; porém, verificou-se um adensamento interno pela ocupação de áreas já consolidadas e boa parte delas já com infraestrutura própria para uso urbano. 
A expansão físico-territorial da cidade de Guarapuava ocorreu predominantemente até 1960, para as direções Norte e Oeste. Na fase seguinte, de 1960 a 1990, houve crescimento em todas as direções, com destaque para as direções Norte, Noroeste, Sudoeste e Sul, enquanto que, após 1990, a cidade se expandiu para as direções Norte, Nordeste, Noroeste e Oeste.

Embora se tenha registro do crescimento urbano de Guarapuava em todas as direções, as regiões Leste e Sudeste chegaram ao seu limite, em função do próprio condicionante físico da região, que apresenta o vale do rio das Pedras, cujo relevo é bastante dissecado, além de ser área de manancial de Guarapuava. Por outro lado, há a tendência de expansão urbana, nas direções Norte e Oeste, sobre terrenos hoje ocupados com atividades agropecuárias.

O conhecimento das direções e da taxa de expansão fisco-territorial urbana e das características socioambientais do território são essenciais para o planejamento urbano e ambiental, uma vez que subsidia os instrumentos de gestão do território, como políticas públicas e planos diretores, no sentido de promover uma ocupação mais adequada do espaço, evitando áreas suscetíveis à riscos ambientais, como inundações e deslizamentos, por exemplo.

\section{REFERÊNCIAS}

BARROS, M. V. F.; BARROS, O. N. F.; CAVIGLIONE, J. H. SIG: uma ferramenta útil na análise urbana. In: ARCHELA, R. S.; FRESCA, T. M.; SALVI, R. F. (Org.). Novas tecnologias. Londrina: UEL, 2001. p. 41-56.

BRASIL. Carta topográfica Guarapuava. Folha SG.22-V-D-III-3, MI-2838/3. Brasília, 1980b. 1 mapa color. Escala 1:50:000.

Carta topográfica Guarapuava. Folha SG.22-V-D-III-3, MI-2838/3. Brasília, 1990b. 1 mapa color. Escala: 1:50:000.

Carta topográfica Guarapuava-O. Folha SG.22-V-D-II-4, MI-2837/4. Brasília, 1990a. 1 mapa color. Escala: 1:50:000.

Exército Brasileiro. DSG - Diretoria de Serviço Geográfico. Carta topográfica

Guarapuava-O. Folha SG.22-V-D-II-4, MI-2837/4. Brasília, 1980a. 1 mapa color. Escala: 1:50:000.

CÂMARA, G. et al. Spring: integrating remote sensing and gis with object-oriented data modelling. Computers and Graphics, New York, v. 15, n. 6, p. 13-22, 1996.

CBERS 2 CCD: imagem de satélite. São José dos Campos: Instituto Nacional de Pesquisas Espaciais, 2005. Bandas 3, 4, 2 e composição colorida. Disponível em:

<http://www.dgi.inpe.br/CDSR/>. Acesso em: 22 maio 2005.

COREDI, R. T.; FERREIRA, S. C. As condições de moradia em Guarapuava como variável analítica sobre o papel de cidade média. In: SCHMIDT, L. P.; COSTA, P. A. (Org.) 
Geografia(s), sociedade e território: leituras na geografia humana. Guarapuava: Unicentro, 2013. p. 119-144.

CORRÊA, R. L. O espaço urbano. São Paulo: Ática, 1995.

ESA. Sentinel Online. Access to sentinel data: European Space Agency. 2017. Disponível em: <https://earthexplorer.usgs.gov/>. Acesso em: 11 abr. 2017.

FLORENZANO, T. G. Imagens de satélites para estudos ambientais. São Paulo: Oficina de Textos, 2002.

GOMES, M. F. V. B. Cartografias da paisagem: trajetória socioambiental de Guarapuava. Guarapuava: UNICENTRO, 2012.

GUARAPUAVA. Prefeitura Municipal. Levantamento aerofotogramétrico da área urbana de Guarapuava. 1996. Escala 1:8:000. 1 CD-ROM.

Lei complementar no 70/2016, de 21 de dezembro de 2016. Dispõe sobre o Plano Diretor do Município de Guarapuava. Guarapuava, 2016.

Lei no 45/1987, de 24 de dezembro de 1987. Institui a Lei de parcelamento do solo para fins urbanos no município de Guarapuava. Guarapuava, 1987.

IBGE. Cidades. Disponível em:

<http://www.ibge.gov.br/cidadesat/painel/painel.php?codmun=410940\#>. Acesso em: 10 fev. 2013.

. Cidades. Guarapuava - PR. Disponível em:

$\overline{<\mathrm{https}}$ ://cidades.ibge.gov.br/brasil/pr/guarapuava>. Acesso em: 13 abr. 2018.

Sinopse do censo demográfico 2010. Rio de Janeiro, 2011. Disponível em:

<http://www.ibge.gov.br/home/estatistica/populacao/censo2010/sinopse.pdf>. Acesso em: 10 fev. 2013.

JENSEN, J. R. Sensoriamento remoto do ambiente: uma perspectiva em recursos terrestres. São José dos Campos: Parêntese, 2009.

LANDSAT: TM 7: imagem de satélite. São José dos Campos: Instituto Nacional de Pesquisas Espaciais, 2002. Banda 3, 4, 5 e composição colorida. Disponível em: <http://www.dgi.inpe.br/CDSR/>. Acesso em: 22 maio 2005.

MARTINELLI, M. Gráficos e mapas: construa-os você mesmo. São Paulo: Moderna, 1998.

MORATO et al. Análise da expansão urbana por meio de composições coloridas multitemporais. Mercator, Fortaleza, v. 10, n. 22, p. 221-231, maio/ago. 2011.

RAPIDEYE: imagem de satélite. Curitiba: Engesat Imagens de Satélite e Geotecnologia, 2011. Imagem geotiff. DVD.

SANTOS, M. A urbanização brasileira. 2. ed. São Paulo: Hucitec, 1993.

SILVA, J. M. Valorização fundiária e expansão urbana recente de Guarapuava-PR. 1995. 167 f. Dissertação (Mestrado em Geografia) - Universidade Federal de Santa Catarina, Florianópolis.

SPÓSITO, M. E. B. As cidades médias e os contextos econômicos contemporâneos. In: (Org.). Urbanização e cidades: perspectivas geográficas. Presidente Prudente: GAsPERR - FCT/UNESP, 2001. p. 609-643.

Capitalismo e urbanização. São Paulo: Contexto, 1988. 
. et al. O estudo das cidades médias brasileiras: uma proposta metodológica. In:

(Org.). Cidades médias: espaços em transição. Presidente Prudente: Expressão

Popular, 2007. p. 35-67.

VESTENA, L. R.; SCHMIDT, L. P. Algumas reflexões sobre a urbanização e os problemas socioambientais no centro centro-sul paranaense. Acta Scientiarum, Human and Social Sciences, Maringá, v. 31, n. 1, p. 67-73, 2009.

\section{AGRADECIMENTOS}

Os autores agradecem a Fundação Araucária e o CNPq, pelo apoio financeiro; ao Ceplug, por ter cedido as fotografias aéreas de 1995, em meio digital; ao DGI/INPE, pela disponibilização das imagens dos satélites LANDSAT e CBERS; à professora Marquiana de Freitas Vilas Boas Gomes, coordenadora do LECAD/DEGEO/Unicentro, pela concessão da imagem do satélite Rapideye; e à Agência Espacial Europeia, por disponibilizar em rede os dados do satélite Sentinel 2.

Recebido: maio de 2017. Aceito: maio de 2018. 